\title{
Microstructure and Mechanical Properties of Ultra-fine-Grained Al-Mg-Si Tubes Produced by Parallel Tubular Channel Angular Pressing Process
}

\author{
G. FARAJI, S. ROOSTAE, A. SEYYED NOSRATI, J.Y. KANG, and H.S. KIM
}

In the present work, commercial Al-6061 alloy tubes were processed via multi-pass parallel tubular channel angular pressing (PTCAP). The effects of the number of passes on grain refinement and mechanical properties were investigated. The microstructural evolution was characterized using electron back-scattered diffraction (EBSD) and scanning electron microscopy. The mechanical properties were evaluated using tensile tests and hardness measurements. The EBSD analyses presented that the elongated subgrains or grains with $\sim 800 \mathrm{~nm}$ in size and a high fraction of low-angle grain boundaries were formed after two PTCAP passes. After four passes, the elongated subgrains have transformed to almost equiaxed grains with $\sim 400 \mathrm{~nm}$ in size and high-angle grain boundaries. Microhardness of the processed tube increased from 38.9 to $63.4 \mathrm{HV}$ ( $\sim 63 \mathrm{pct})$ after three PTCAP passes. An increase in the number of PTCAP passes after three passes has no more effect on the microhardness. Yield and ultimate tensile strength were increased by 2.1 and 1.6 times, respectively, after four PTCAP passes $(\varepsilon \sim 6.4)$ compared to the annealed sample. Ductile fracture with an extensive necking zone and many big dimples occur in the annealed sample, while fine dimples and limited ductile fracture features were observed in the ultra-fine grained PTCAP-processed samples.

DOI: $10.1007 / \mathrm{s} 11661-015-2740-8$

(C) The Minerals, Metals \& Materials Society and ASM International 2015

\section{INTRODUCTION}

PROCESSING and characterization of the ultra-finegrained (UFG) and nanostructured (NS) materials produced using severe plastic deformation (SPD) techniques ${ }^{[1]}$ have received much attention during past two decades due to their enhanced room temperature strength and high-temperature superplastic properties. Many SPD techniques, such as equal channel angular pressing (ECAP),${ }^{[2-6]}$ high-pressure torsion (HPT),${ }^{[7]}$ and accumulative roll bonding (ARB) ${ }^{[8,9]}$ were applied for processing of bulk or sheet-shaped UFG materials. These methods are, however, incapable of processing tubular-shaped parts.

During the last 5 years, different SPD methods such as accumulative spin bonding (ASB) ${ }^{[10]}$ high-pressure tube twisting (HPTT) ${ }^{[11]}$ and modified ECAP ${ }^{[12]}$ were developed for processing of tubular samples. Recently, two novel SPD methods, i.e., parallel tubular channel angular pressing (PTCAP $)^{[13]}$ and tubular channel angular pressing (TCAP), ${ }^{[1,15]}$ have been proposed by Faraji et al. for a fabrication of UFG and NS material tubes. Among them, the PTCAP process has some

G. FARAJI, Assistant Professor, and S. ROOSTAE and A. SEYYED NOSRATI, MSc. Students, are with the School of Mechanical Engineering, College of Engineering, University of Tehran, 11155-4563 Tehran, Iran. Contact e-mail: ghfaraji@ut.ac.ir J.Y. KANG, PhD Student, and H.S. KIM, Professor, are with the Department of Materials Science and Engineering, POSTECH, Pohang 790-784, Korea.

Manuscript submitted July 19, 2014

Article published online 13 January 2015 advantages, such as lower process load and better strain homogeneity compared to the TCAP process. ${ }^{[16]}$ The PTCAP process could achieve significant grain refinements and a notable increase in strength of the copper tube after a single PTCAP pass. Processing of UFG AZ91 and NS pure aluminum tubes has been performed using the TCAP process by Faraji et al. ${ }^{[17]}$ and Mesbah et al. ${ }^{[18]}$ Mesbah et al. ${ }^{[18]}$ presented that NS aluminum tubes with high-angle grain boundaries (HAGBs) could be produced using the TCAP process at an equivalent plastic strain of $\sim 8$.

Despite extensive applications of aluminum and its alloys in various industries, processing of UFG aluminum tubes using the PTCAP process has not been done yet. Precipitation strengthened and age hardening aluminum alloys are some of the most promising candidates for a production of thermally stable high-strength UFG materials. It has been reported that approximately two-thirds of all extrudates are made of aluminum alloys, and 90 pet of them are within the 6xxx series. ${ }^{[19]}$ Furthermore, among many aluminum alloys currently available, the age-hardenable Al-6061 alloy is extensively used in various industrial applications because it provides a good combination of formability and strength.

Many reports described the processing of Al-6061 alloy using ECAP, ${ }^{[20-22]} \mathrm{HPT}^{[23,24]}$ and $\mathrm{ARB}^{[25-27]}$ processes, in contrast no investigation was made for the processing and characterization of Al-6061 alloy using the PTCAP process. In this study, the multi-pass PTCAP process was applied to produce UFG Al-6061 alloy tubes. The effect of the number of PTCAP passes 
on microstructural and mechanical properties was studied.

Figure 1 shows the principle of PTCAP process which consists of two half cycles. In the first half cycle, the first punch extrudes the initial tube into the tubular angular channel with two axisymmetric shear regions, as shown in Figure 1(a), which expands the tube diameter. In the second half cycle, the second punch extrudes the tube material back into the same shear regions from the other end of the tube, as shown in Figure 1(b). At the beginning and end of the PTCAP process, the tube cross section remains unchanged. In the multi-pass PTCAP process, distinct strains are obtained by repeating of the process many times as needed.

Considering the circumferential and radial strains in the PTCAP process, ${ }^{[28]}$ the following relationship is used to calculate the accurate value of total accumulated strain $\left(\bar{\varepsilon}_{T}\right)$ in the first half cycle of the PTCAP process in the geometry of Figure $1:^{[13]}$

$\bar{\varepsilon}_{T}=\sum_{i=1}^{2}\left[\frac{2 \cot \left(\varphi_{i} / 2+\psi_{i} / 2\right)+\psi_{i} \operatorname{cosec}\left(\varphi_{i} / 2+\psi_{i} / 2\right)}{\sqrt{3}}\right]+\bar{\varepsilon}_{\theta}$,

$$
\begin{aligned}
& \bar{\varepsilon}_{\theta}=\frac{2}{\sqrt{3}} \varepsilon_{\theta}, \\
& \varepsilon_{\theta}=\ln \frac{R_{2}}{R_{1}},
\end{aligned}
$$

Finally, the total equivalent strain after $N$ passes of PTCAP can be expressed in a general form by the following relationship:

$$
\begin{aligned}
\bar{\varepsilon}_{T N} & =2 N \\
& \left\{\sum_{i=1}^{2}\left[\frac{2 \cot \left(\varphi_{i} / 2+\psi_{i} / 2\right)+\psi_{i} \operatorname{cosec}\left(\varphi_{i} / 2+\psi_{i} / 2\right)}{\sqrt{3}}\right]+\bar{\varepsilon}_{\theta}\right\} .
\end{aligned}
$$

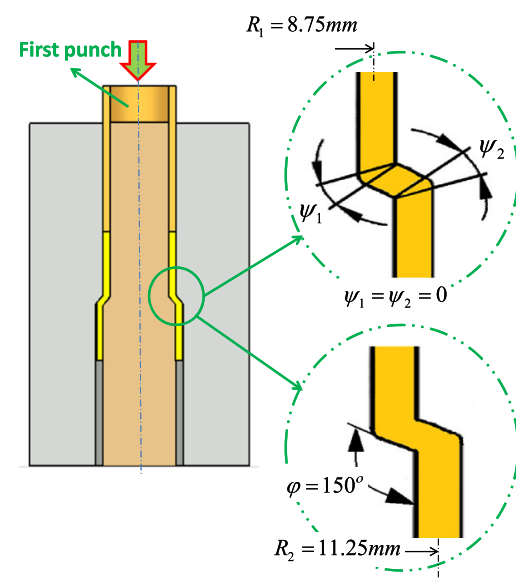

(a)

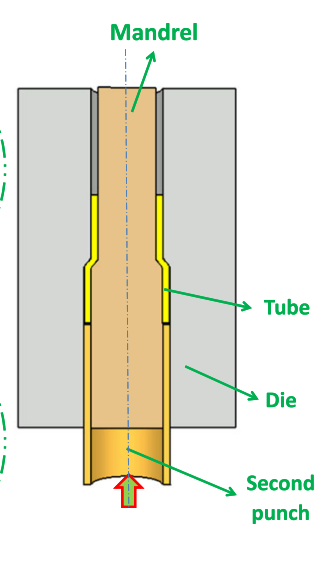

(b)
Fig. 1-Schematics of the PTCAP process in the $(a)$ first and $(b)$ second half cycles.
The total equivalent plastic strains considering the die parameters used in the current work are $\sim 1.6, \sim 3.2, \sim 4.8$, and $\sim 6.4$ after applying one, two, three, and four passes, respectively.

\section{EXPERIMENTAL PROCEDURE}

The A1-6061 alloy sample with chemical composition of 0.607 pet $\mathrm{Si}, 1.08$ pet $\mathrm{Mg}, 0.2$ pct $\mathrm{Cu}, 0.27$ pet $\mathrm{Fe}$, 0.067 pet $\mathrm{Cr}$, and $\mathrm{Al}$ bal. were used. Original tubes of $2.5 \mathrm{~mm}$ in thickness, $20 \mathrm{~mm}$ in diameter, and $50 \mathrm{~mm}$ in length were machined from the Al alloy rod. Prior to the

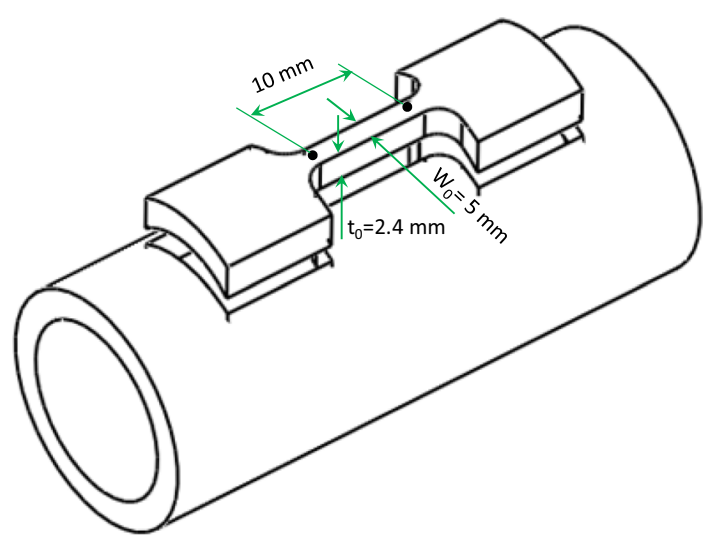

Fig. 2-Configuration of the tensile specimens from the tube.

Table I. The Properties of Al-6061

\begin{tabular}{lcccc}
\hline Material & $\begin{array}{c}\text { Tensile } \\
\text { Strength } \\
(\mathrm{MPa})\end{array}$ & $\begin{array}{c}\text { Yield } \\
\text { Strength } \\
(\mathrm{MPa})\end{array}$ & $\begin{array}{c}\text { Elongation } \\
(\mathrm{pct})\end{array}$ & $\begin{array}{c}\text { Hardness } \\
(\mathrm{Hv})\end{array}$ \\
\hline AA6061 & 116 & 76 & 13 & 38.9 \\
\hline
\end{tabular}

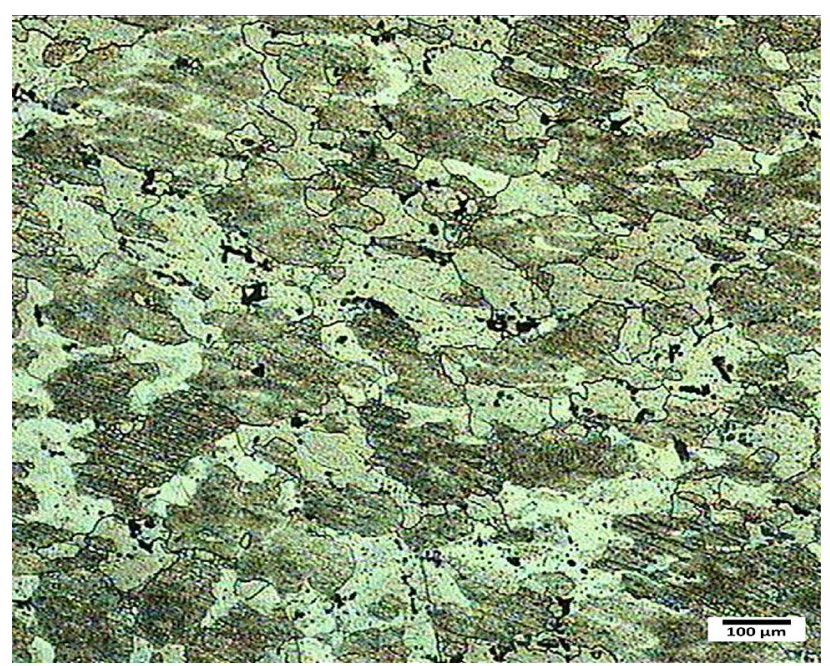

Fig. 3-Optical microscopy microstructure of annealed Al-6061 before PTCAP processing. 
PTCAP process, a recrystallized homogeneous microstructure was obtained by heating the samples to $873 \mathrm{~K}$ $\left(600{ }^{\circ} \mathrm{C}\right)$ for 2 hours. The microstructure of the Al-6061 primary tube before the PTCAP process, including recrystallized grains with an initial grain size of $\sim 100 \mu \mathrm{m}$, is shown in Figure 3.

The material used for the PTCAP die including mandrel, die, and punches was made of $\mathrm{H} 13$ tool steel
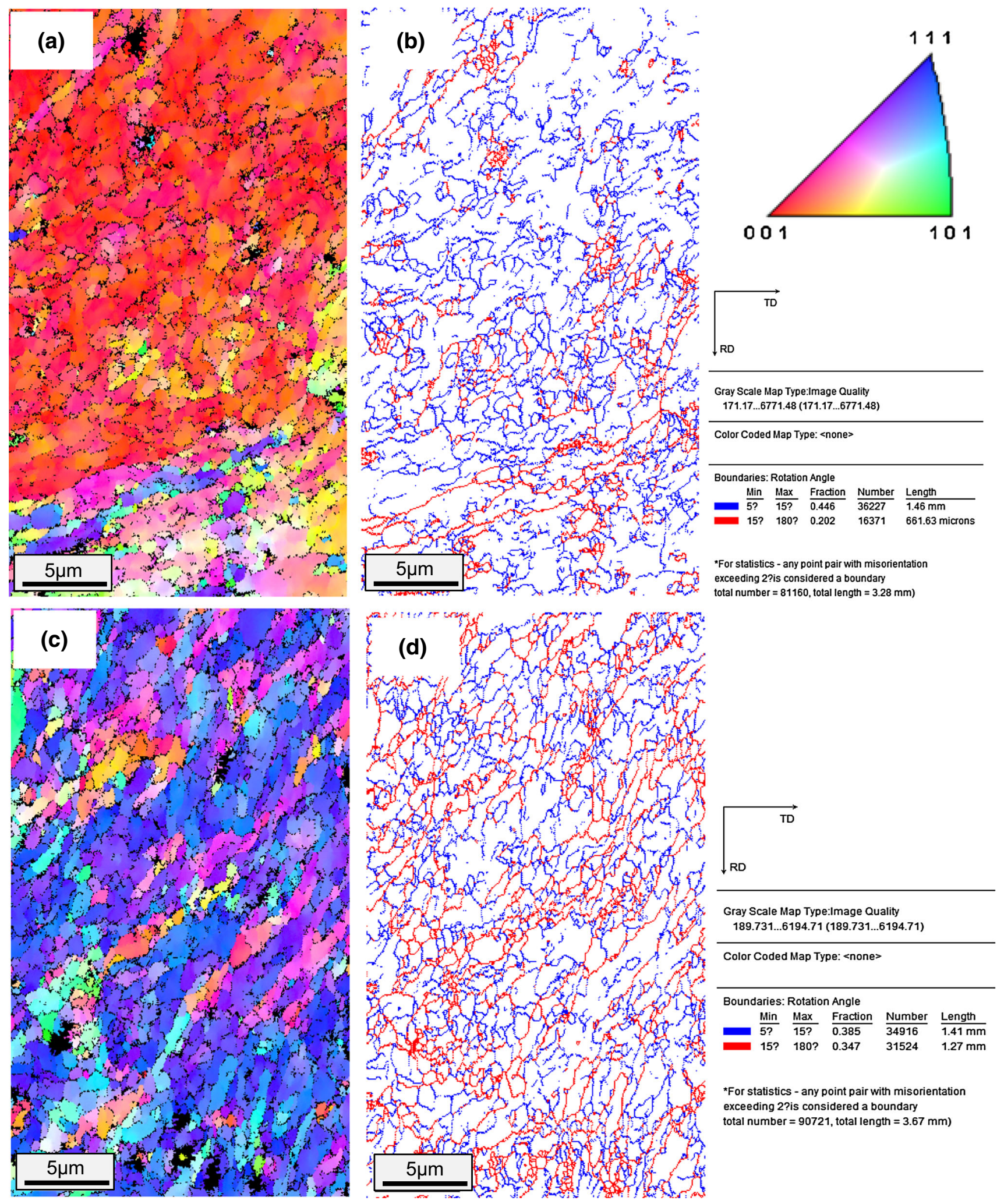

Fig. 4-The EBSD orientation imaging map (OIM) patterns, pole figures, and inverse pole figures of $(a)$ two and $(c)$ four passes processed sample; and boundary maps of $(b)$ two and $(d)$ four passes processed samples. 


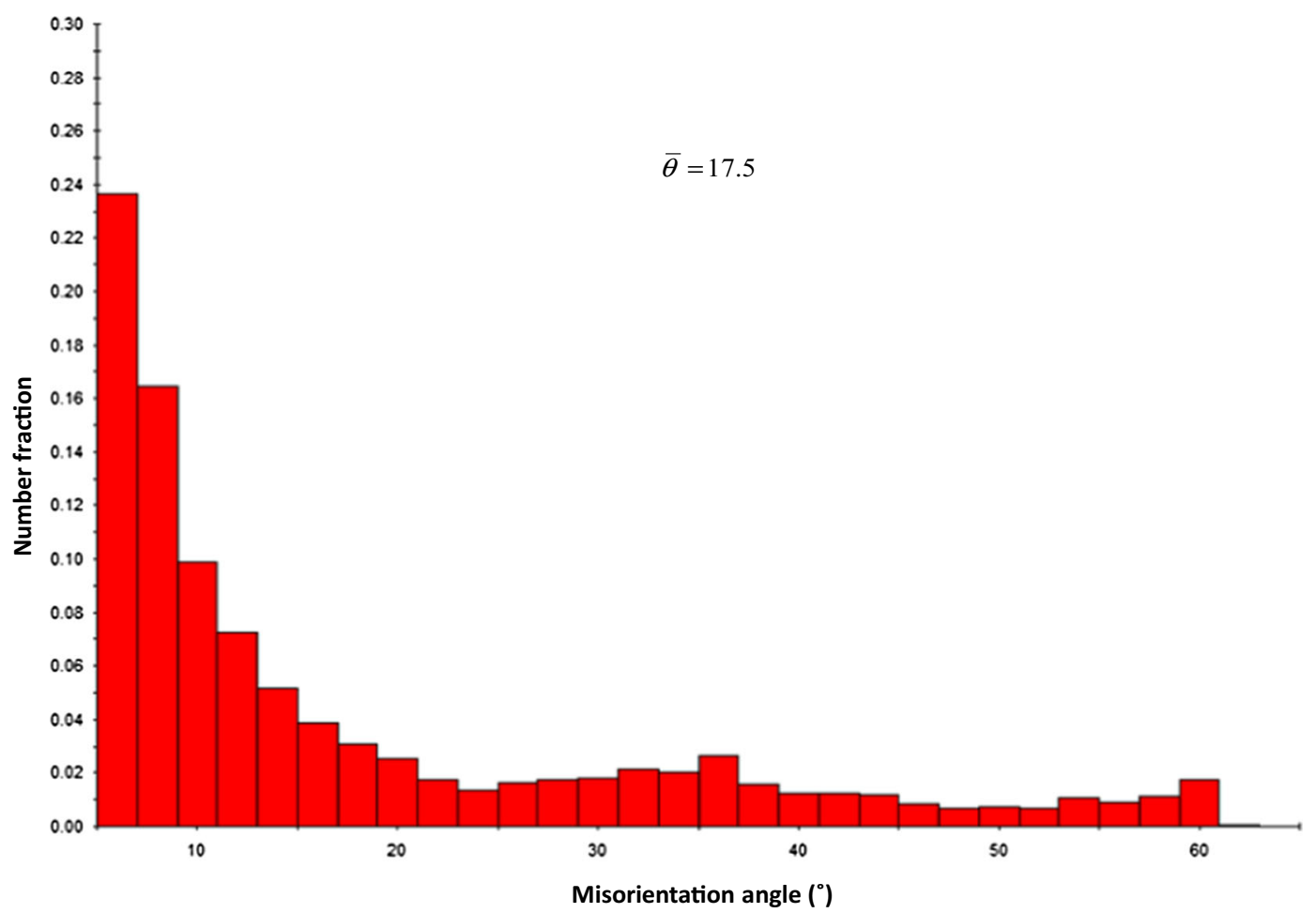

(a)

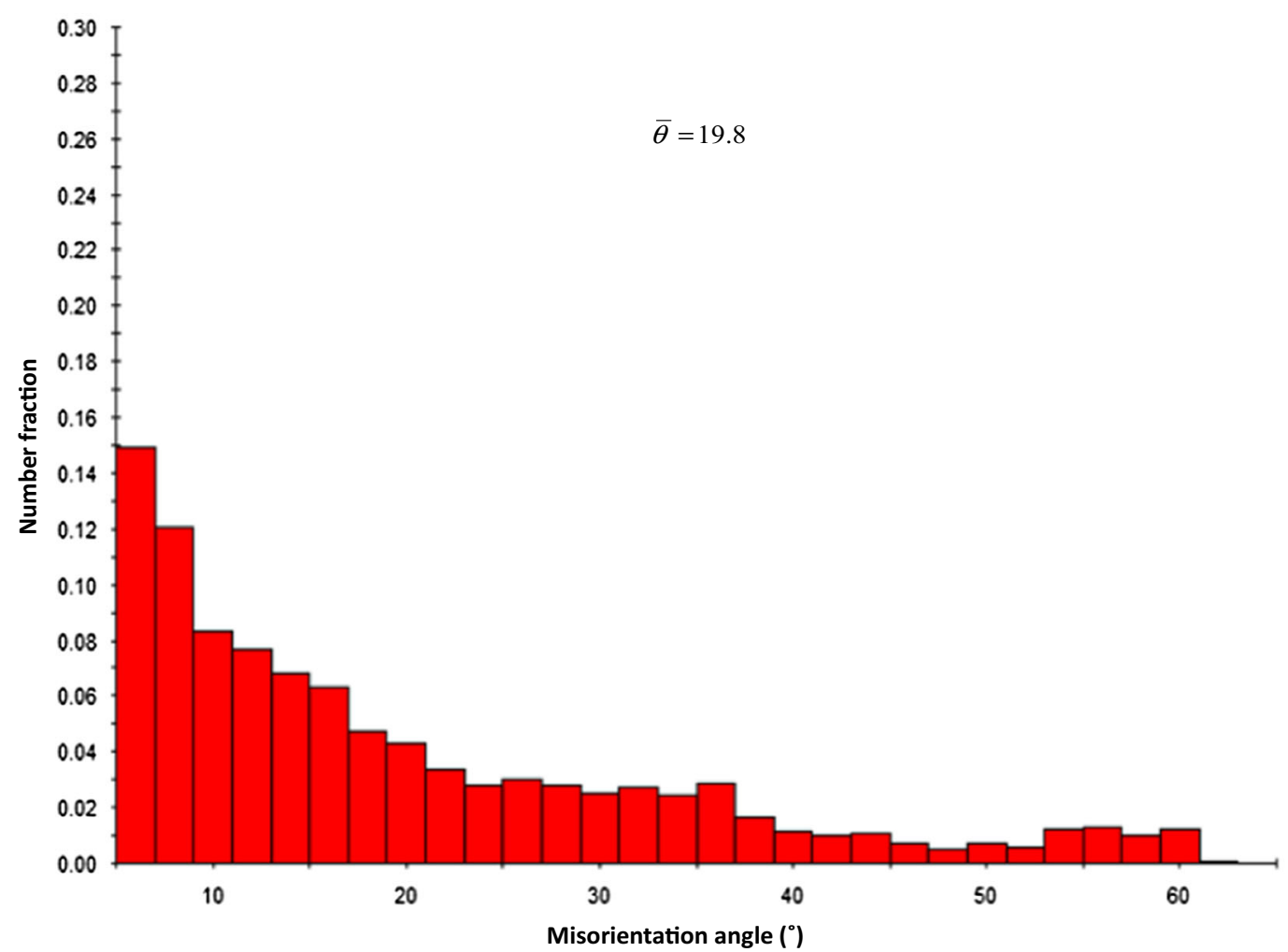

(b)

Fig. 5-Misorientation angle distributions in the $(a)$ two pass $(b)$ four pass PTCAP-processed samples. 
which was hardened to $\sim 55$ HRC. Before pressing the tube, a $\mathrm{MoS}_{2}$ lubricant was used to decrease friction between the tubes and dies. ${ }^{\left[{ }^{29]}\right.}$ Die parameters including the channel angle $\varphi$, the angle of curvature $\psi_{1}\left(=\psi_{2}\right)$, radii $R_{1}$ and $R_{2}$, and their values are presented in Figure 1. A pressing speed of $5 \mathrm{~mm} / \mathrm{min}$ was used to perform the PTCAP experiments at room temperature.

Microstructure of the PTCAP-processed tube was investigated using electron back-scattered diffraction (EBSD) and scanning electron microscopy (SEM). The transverse (top) surfaces of the tube PTCAP-processed samples were polished to obtain mirror-like surfaces for accurate EBSD measurements. After polishing using silicon carbide papers (sandpapers) of 180, 400, 600, 800 , and 1200 grits in order, 3 and $1 \mu \mathrm{m}$ alcohol-based diamond suspensions and $0.04 \mu \mathrm{m}$ colloidal silica suspension were used to produce the mirror-like surfaces. EBSD analysis was conducted using a 3D Total Analysis instrument equipped with a field-emission gun (Hikari EBSD detector) with a step size of $70 \mathrm{~nm}$. The EBSD data were analyzed using the TSL OIM analysis software. All points with a confidence index (CI) lower than 0.05 were removed in order to use more reliable and correct data during the EBSD microstructural analysis. Furthermore, misorientation angles less than 5 deg were excluded. The grain sizes less than five times the step size were also excluded from the grain size calculations.

Microhardness measurements were performed by $300 \mathrm{~g}$ load applied for 10 seconds. Three microhardness measurements (for each sample) have been done at the middle of the thickness of PTCAP-processed tube cross section of perpendicular to axis direction. Tensile specimen dimensions of the annealed and after 1,2, 3, and 4 passes PTCAP are shown in Figure 2. Tensile test specimens were machined parallel to the longitudinal axis of the PTCAP-processed samples using a wire cut EDM machine. An INSTRON tensile testing machine was used to carry out the tests at room temperature at the strain rate of $1.3 \times 10^{-3} \mathrm{~s}^{-1}$. The load vs displacement was obtained and converted to the relationship of stress $v s$ strain. Two tensile tests have been done for the stress/strain calculation. The Al-6061 tensile properties are given in Table I. SEM was used to characterize the fracture surfaces of the fractured tensile specimens (Figure 3).

\section{RESULTS AND DISCUSSION}

Figures 4(a) and (c) present the EBSD orientation imaging map (OIM) patterns of the two and four passes PTCAP-processed samples, respectively. The texture ranged from (100) to (101) and (111) in two and four passes, respectively; that can be seen as red and blue grains in the inverse pole figure (IPF). As can be seen in Figure 4(a), there are a few elongated subgrains and a lot of equiaxed grains and subgrains with a high fraction of low-angle grain boundaries after two passes $(\varepsilon \sim 3.2)$. Continuous recrystallization may form equiaxed grains. Recrystallized grains in FCC metals, because of the large deformations at room temperatures, have been reported by some researchers. ${ }^{[30,31]}$ Results from optical microscopy analysis of four pass ECAP-processed Al6061 samples showed that most of the elongated grains became uniformly distributed, ${ }^{[32]}$ which is inconsistent with two passes PTCAP-processed sample microstructure shown in Figure 4(a).

The EBSD micrographs of PTCAP-processed sample through four passes $(\varepsilon \sim 6.4)$ are shown in Figure 4(c). As can be seen the subgrains in the micrographs of Figure 4(a) transformed to equiaxed grains with highangle grain boundaries in four passes processed sample IPF shown in Figure 4(c). Figures 4(b) and (d) shows the corresponding grain boundary maps of Figures 4(a) and (c), respectively. The blue lines indicate the highangle grain boundaries with a misorientation angle above $15 \mathrm{deg}$ and low-angle boundaries with the red lines. After two passes, low-angle misorientations are dominants in the boundaries (Figure 4(b)), but highangle grain boundaries are dominant after four passes (Figure 4(d)).

The histograms for the misorientation angle of the two and four passes PTCAP-processed samples are shown in Figure 5. After two passes of the PTCAP process (Figure 5(a)), the microstructure consists of

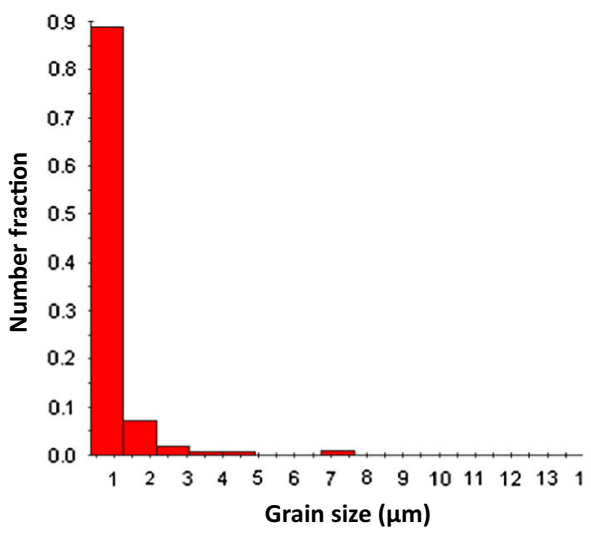

(a)

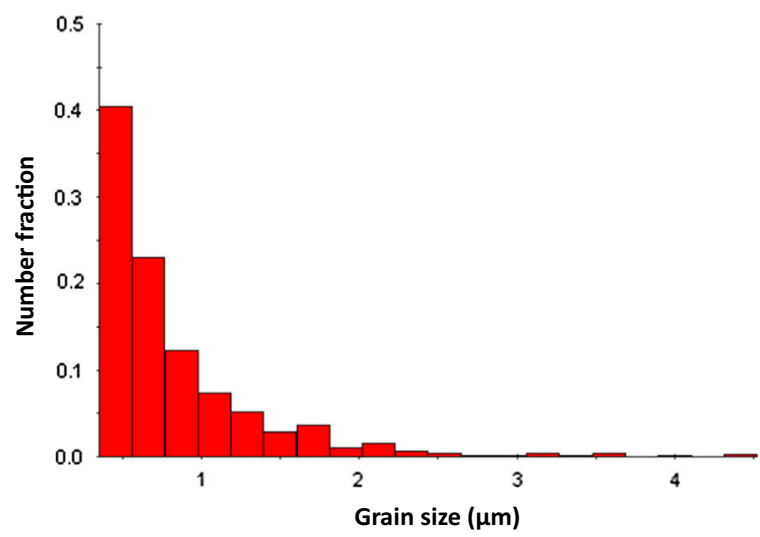

(b)

Fig. 6- Grain size distributions in the (a) two pass and (b) four pass PTCAP-processed samples. 
-39 pct of high-angle grain boundaries with a mean boundary angle of $\sim 17.5 \mathrm{deg}$, but the area fraction of the high-angle grain boundaries after four passes is $\sim 52$ pct with a mean boundary angle of 19.8 deg (Figure 5(b)). It is clear that the fraction of high-angle grain boundaries increase as the number of PTCAP passes increases. The applied strain indicates the subgrain misorientation angle distribution. Misorientation changes from low- to high-angle at each pass due to the strain evolution.

Low grain interior dislocation densities were present in the most of the grown grains after the two pass. It may be expected that the smaller equiaxed grains virtually without dislocations are developed in the higher number of passes processed sample because the UFG materials with smaller grain size compared to fine-

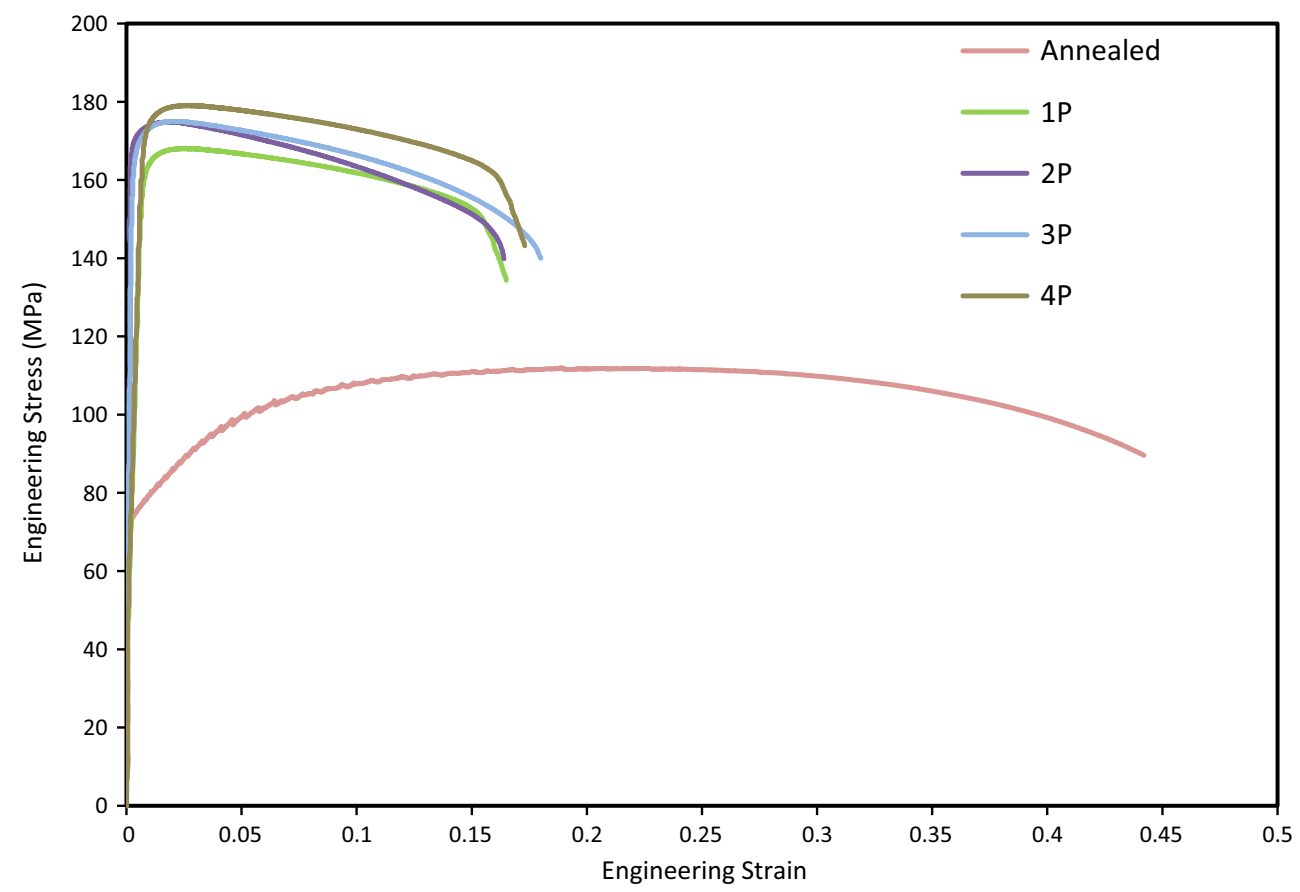

(a)
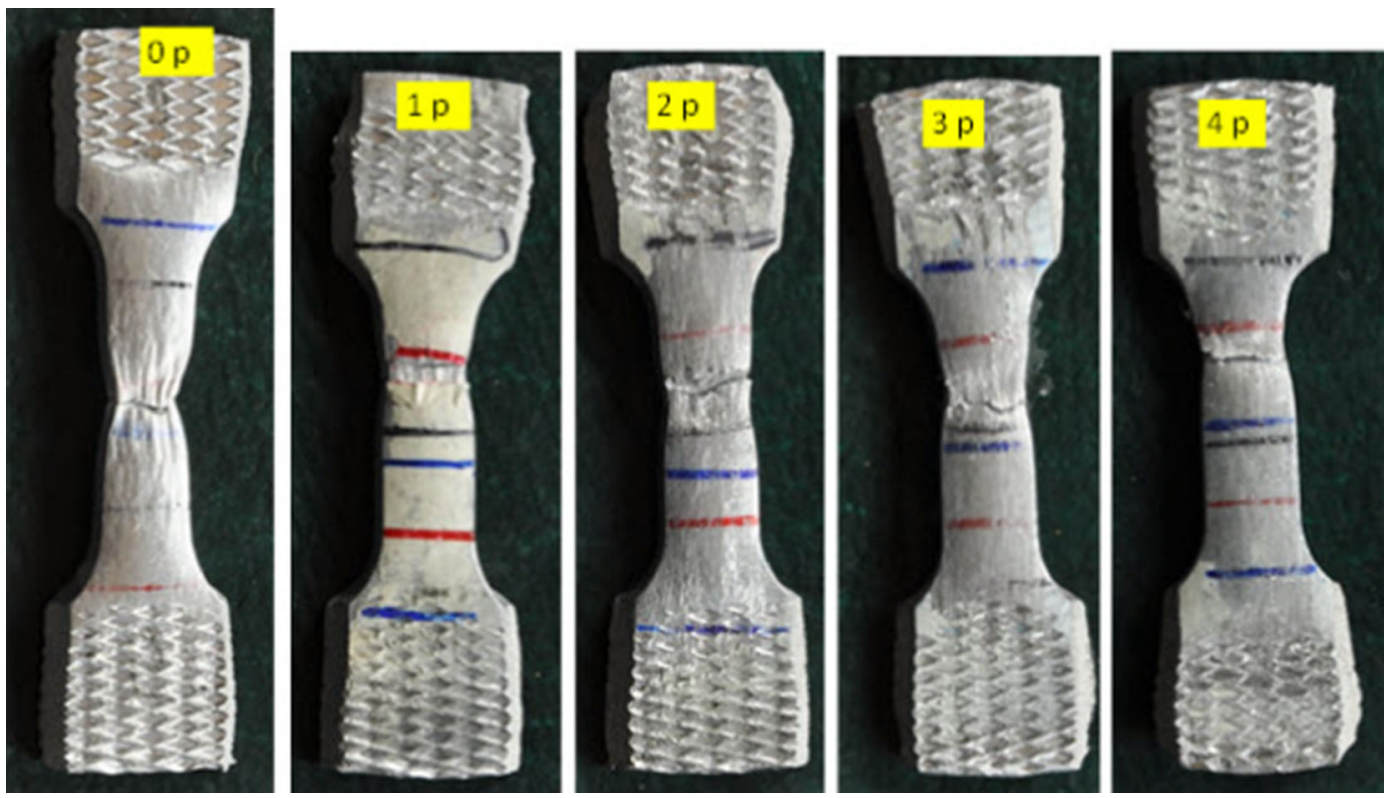

(b)

Fig. 7-(a) Engineering stress-strain curves of the annealed and processed Al-Mg-Si tubes through 1-4 pass PTCAP resulted from tensile tests and $(b)$ the tensile test samples after fracture. 
grained materials have a lower work hardenability. ${ }^{[33]}$ The density of dislocations in the grain interiors decreases due to an increase in the number of PTCAP passes. ${ }^{[16]}$

The histograms for grain size distributions of the two and four passes PTCAP-processed samples are shown in Figures 6(a) and (b), respectively. The mean grain sizes of the two passes and four passes PTCAP-processed samples are $\sim 800$ and $\sim 400 \mathrm{~nm}$, respectively. It is obvious from histograms (Figures 6(a) and (b)) and Figure 3 that the elongated subgrains with $\sim 100 \mu \mathrm{m}$ in size in the initial sample transform to a combination of new grains and subgrains with $\sim 800 \mathrm{~nm}$ in size in the two passes processed sample. Elongated grains and subgrains almost vanish, and equiaxed grains with grain size $\sim 400 \mathrm{~nm}$ are formed as the number of PTCAP passes increases to four. There are many reports on SPD processing of aluminum alloys. The mean grain size of $800 \mathrm{~nm}$ after 12 ECAP passes (route Bc) for Al-6061processed sample $(\varepsilon \sim 12)$ was reported by Tham et al. ${ }^{[32]}$

Tensile tests performed on the annealed and 1 to 4 passes PTCAP-processed samples are shown in Figure 7(a). The obvious strain hardening, lower-tensile strength $(116 \mathrm{MPa})$, and larger elongation ( 43 pct have occurred in the annealed sample with coarse grain of $\sim 100 \mu \mathrm{m}$ in size. It is clear that the little strain hardening has occurred in PTCAP-processed samples and the elongation of the PTCAP-processed samples decreases mostly due to the work hardening and accumulation of dislocation networks. As expected, the strength of the PTCAP samples increases significantly over the initial sample. Figure 8 shows the effect of the number of PTCAP passes on the ultimate strength, yield strength, and elongation of the samples. The annealed sample has the UTS of $\sim 116 \mathrm{MPa}$ with $\sim 43$ pct elongation due to the annealing heat treatment conducted before PTCAP. After one pass, the UTS increases to the value of $179 \mathrm{MPa}$ (54 pct increase) as a result of grain refinement while the elongation decreases $\sim 62 \mathrm{pct}$ Increase in accumulated strain with decrease in hardening exponent reduces elongation after the PTCAP process. UTS increases to $\sim 180 \mathrm{MPa}$ (55 pct increase) with $\sim 16$ pct elongation for 2 PTCAP passes. After four PTCAP passes, UTS increases to $190 \mathrm{MPa}$ and the elongation remains almost constant. The highest UTS with lower elongation $(\sim 16.5 \mathrm{pct})$ can be obtained after 4 PTCAP passes, as shown in Figure 8. The dislocations movement is obstructed in ultra-fine grains with high-angle grain boundaries. So the strength of material increases. ${ }^{[34]}$

The pictures of the fractured tensile annealed and PTCAP-processed samples are shown in Figure 7(b). As can be seen, a large plastic deformation and large necking zone occurred before fracture in the annealed sample, while a small necked zone could be observed in the UFG PTCAP-processed samples. These images could verify the tensile data obtained from the tensile tests.

Figure 9 shows the Vickers Microhardness (HV) of Al-6061 alloy $v s$ the number of PTCAP passes taken on the tube cross section normal to the extrusion direction. As is observed, hardness increases from 38.9 to $60.6 \mathrm{HV}$

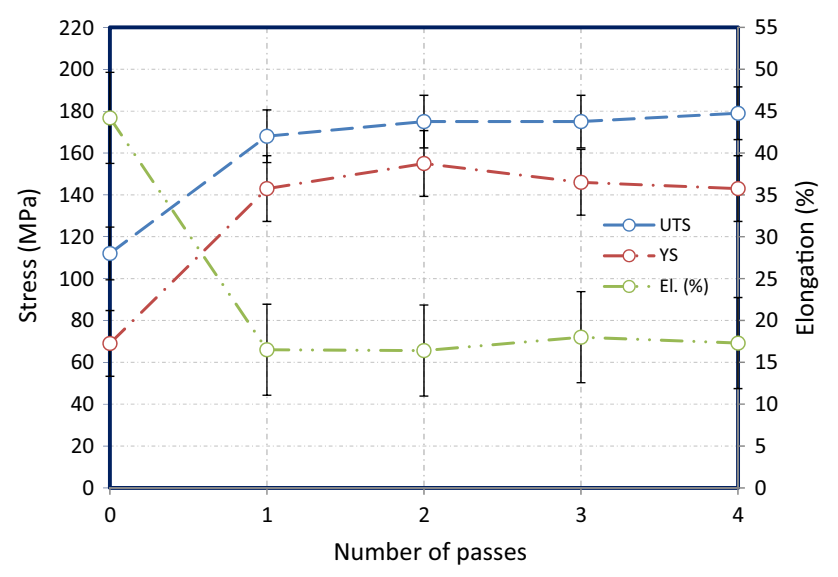

Fig. 8-UTS, YS and elongation $v$ s the number of PTCAP passes.

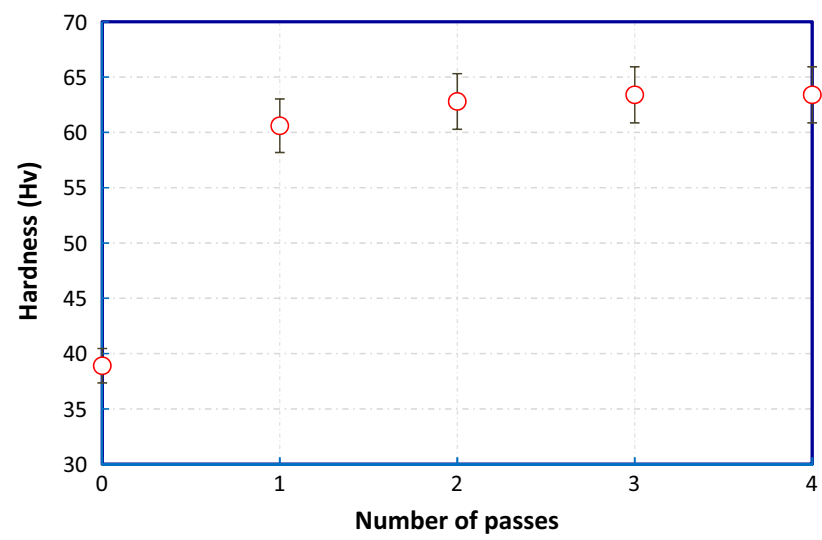

Fig. 9-Microhardness of the processed tube $v s$ number of PTCAP passes.

( 55 pct increase) in the samples after 1 PTCAP passes. Microstructure refinement resulted from SPD increase the hardness after 1 passes of PTCAP of Al-6061 alloy. Also, the hardness of the samples increased to $62.8 \mathrm{HV}$ $(\sim 61 \mathrm{pct})$ after 2 PTCAP passes. Reduction in the grain size from $100 \mu \mathrm{m}$ (Figure 3) to $\sim 800 \mathrm{~nm}$ (Figure 6) increases in hardness after 2 PTCAP passes. Hardness increases further to $63.4 \mathrm{HV}$ (62.9 pct) after processing samples for 3 PTCAP passes. The highest hardness value obtained after 3 PTCAP passes. The increase in hardness could be due to the grain refinement after 3 PTCAP passes. It has been said that the small grain size reduction occurs after 3 PTCAP passes. In general, the hardness increases with an increase the number of PTCAP passes. As can be seen, increasing of the number of PTCAP passes after 3 passes has not more effect on the microhardness. The saturation is may be because of the saturation of the grain size. This saturation behavior has also seen in ECAP-processed copper, ${ }^{[30]} \mathrm{Ni},{ }^{[35]} \mathrm{Ti},{ }^{[36]}$ and magnesium alloy ${ }^{13]}$ and TCAP-processed pure Al. ${ }^{[18]}$ Some researchers reported that the increase in the strain reduces the dislocation density in the grain interiors of a $1050-\mathrm{Al}$ alloy. ${ }^{[37]} \mathrm{So}$, most of the grain interiors with less dislocations are present after a severe deformation. 

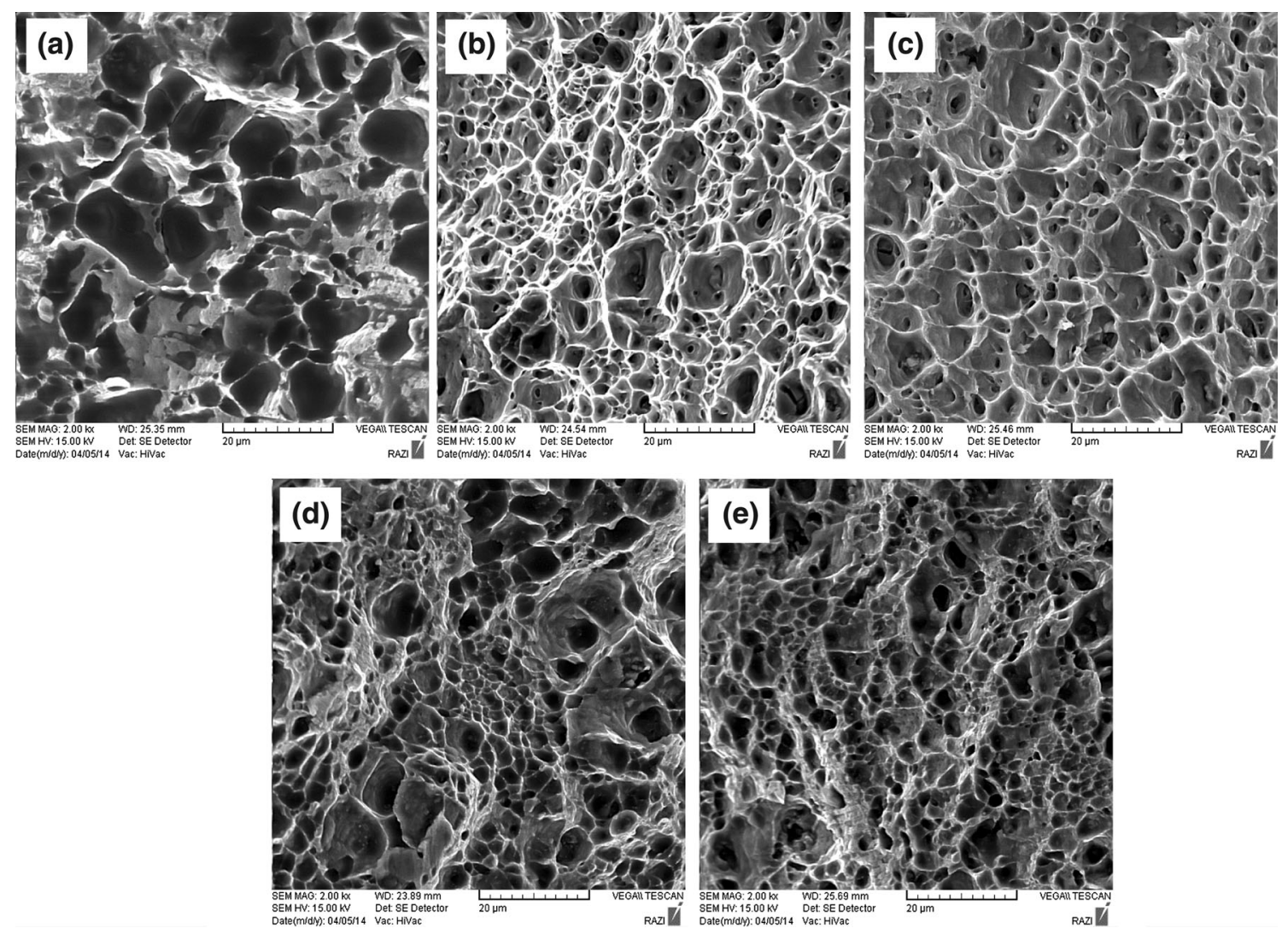

Fig. 10 - SEM micrograph of the cross section of fractured $(a)$ annealed, $(b)$ one pass, $(c)$ two passes, $(d)$ three passes, and $(e)$ four passes PTCAP-processed tensile samples.

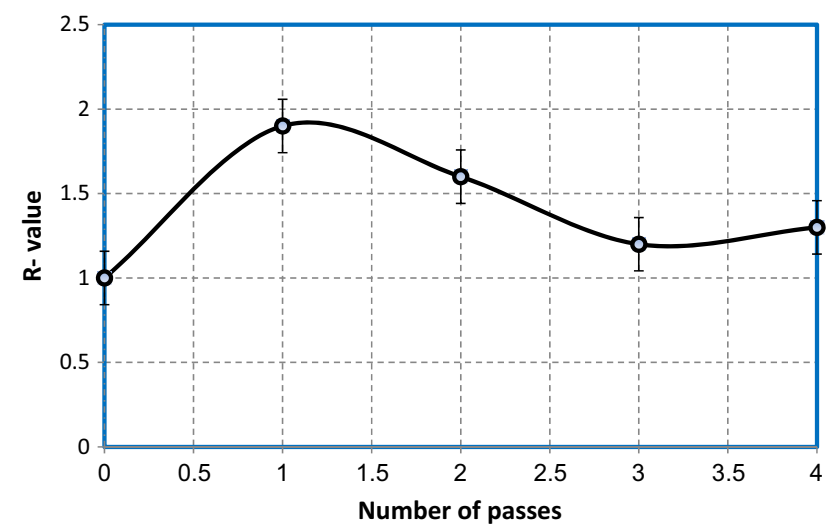

Fig. $11-R$-value $v s$ the number of PTCAP passes.

The fracture surface of the initial and multi-pass PTCAP-processed samples (tensile specimens) is shown in Figure 10. Ductile fracture with many big dimples occurred in the annealed sample (Figure 10(a)). Fine dimples and limited ductile fracture features are observed in Figures 10(b) through (e), which correspond to UFG PTCAP-processed samples. In other words, after one passes PTCAP processing, the number of dimples increases and the size of the dimples is finer, as shown in Figure 10(b). After four passes PTCAP process, the size of dimples decreases slightly. It is clear that the annealed sample has the highest ductility due to its largest dimple size. This result is consistent with tensile results shown in Figure 8. In fact, in the UFG material, the shallower dimples present in comparison with a very deep holes in the annealed sample due to a decrease in ductility during PTCAP, which is attributed to the deformation in the ultra-fine grains by the dislocation movements. This illustrates the increase in the hardening during the tensile tests in the multi-pass PTCAP samples, which is related to the development of obstacles to retard the movement of dislocations.

The state of anisotropy was estimated using the $R$ value which was defined as $R=\frac{\varepsilon_{w}}{\varepsilon_{t}}$, where $\varepsilon_{w}=\ln \frac{w}{w_{0}}$ and $\varepsilon_{t}=\ln \frac{t}{t_{0}}$ indicate width strain and thickness strain, respectively. ${ }^{[38]}$ Figure 11 exhibits the $R$-value $v_{s}$ the number of PTCAP passes during tensile tests. It is clear that the $R$-value is equal to 1 for the annealed sample, indicating the isotropic initial state. As is observed, the $R$-value increases from 1 to 1.9 in the samples after the 1 st PTCAP pass. Then, the $R$-value decreases to 1.6 after the 2nd PTCAP pass. After the 3rd PTCAP pass, the $R$-value decreases to 1.2. The $R$-value increases to 1.3 marginally after the 4 PTCAP passes. This $R$-value trend results from the texture evolution: that is, the deformation texture develops significantly in the 1 st past and afterwards weakened due to grain refinements. The texture evolution is important in many mechanical properties and phenomena, hence need more and deeper investigation. 


\section{CONCLUSIONS}

Ultra-fine-grained (UFG) aluminum alloy tubes were fabricated using the parallel tubular channel angular pressing (PTCAP) process. EBSD results demonstrated that after two PTCAP passes, the elongated subgrains or grains with $\sim 800 \mathrm{~nm}$ in size and a high fraction of lowangle grain boundaries are formed. After four passes, the elongated subgrains have transformed to almost equiaxed grains with $\sim 400 \mathrm{~nm}$ in size and high-angle grain boundaries. Microhardness of the processed tube increased from 38.9 to $63.4 \mathrm{HV}$ ( $\sim 62.9$ pct increase) after 3 PTCAP passes. Increasing of the number of PTCAP passes after 3 passes has not more effect on the microhardness. Yield and ultimate tensile strengths were increased by 2.1 and 1.6 times after four PTCAP passes $(\varepsilon \sim 6.4)$, respectively, compared to the annealed sample. Ductile fracture with a large necking zone and many big dimples occurred in the annealed sample, while fine dimples and limited ductile fracture features were observed in UFG PTCAP-processed samples.

\section{ACKNOWLEDGMENTS}

This work was financially supported by Iran National Science Foundation (INSF).

\section{REFERENCES}

1. R.Z. Valiev, R.K. Islamgaliev, and I.V. Alexandrov: Prog. Mater. Sci., 2000, vol. 45, pp. 103-89.

2. K. Matsuki, T. Aida, T. Takeuchi, J. Kusui, and K. Yokoe: Acta Mater., 2000, vol. 48, pp. 2625-32.

3. M.S. Soliman, E.A. El-Danaf, and A.A. Almajid: Mater. Sci. Eng. A, 2012, vol. 532, pp. 120-29.

4. Y. Chen, Y. Chai, H. Roven, S. Gireesh, Y. Yu, and J. Hjelen: Mater. Sci. Eng. A, 2012, vol. 545, pp. 139-47.

5. J. Zhang, K.-S. Zhang, H.-C. Wu, and M.-H. Yu: Trans. Nonferrous Met. Soc. China, 2009, vol. 19, pp. 1303-11.

6. M. Cabibbo: Mater. Charact., 2010, vol. 61, pp. 613-25.

7. G. Faraji and P. Asadi: Mater. Sci. Eng. A, 2011, vol. 528, pp. $2431-40$.

8. M. Reza Toroghinejad, F. Ashrafizadeh, R. Jamaati, M. Hoseini, and J.A. Szpunar: Mater. Sci. Eng. A, 2012, vol. 556, pp. 351-57.

9. M. Eizadjou, H.D. Manesh, and K. Janghorban: J. Alloy Compd., 2009, vol. 474, pp. 406-15.

10. M.S. Mohebbi and A. Akbarzadeh: Mater. Sci. Eng. A, 2010, vol. 528 , pp. $180-88$.
11. L.S. Tóth, M. Arzaghi, J.J. Fundenberger, B. Beausir, O. Bouaziz, and R. Arruffat-Massion: Scripta Mater., 2009, vol. 60, pp. 17577.

12. F. Djavanroodi, M. Daneshtalab, and M. Ebrahimi: Mater. Sci. Eng. A, 2012, vol. 535, pp. 115-21.

13. G. Faraji, A. Babaei, M.M. Mashhadi, and K. Abrinia: Mater. Lett., 2012, vol. 77, pp. 82-85.

14. G. Faraji, M.M. Mashhadi, and H.S. Kim: Mater. Sci. Eng. A, 2011, vol. 528, pp. 4312-17.

15. G. Faraji, M.M. Mosavi, and H.S. Kim: Mater. Trans., 2012, vol. 53 , pp. 8-12.

16. G. Faraji, M.M. Mashhadi, A.R. Bushroa, and A. Babaei: Mater. Sci. Eng. A, 2013, vol. 563, pp. 193-98.

17. G. Faraji, P. Yavari, S. Aghdamifar, and M.M. Mashhadi: $J$. Mater. Sci. Technol., 2014, vol. 30, pp. 134-38.

18. M. Mesbah, G. Faraji, and A.R. Bushroa: Mater. Sci. Eng. A, 2014, vol. 590, pp. 289-94

19. H.S. Kim, M.H. Seo, and S.I. Hong: J. Mater. Process. Technol., 2001, vol. 113 , pp. 622-26.

20. Q. Jining, Z. Di, Z. Guoding, and J.-C. Lee: Mater. Sci. Eng. A, 2005, vol. 408 , pp. $79-84$.

21. A.S. Khan and C.S. Meredith: Int. J. Plast., 2010, vol. 26, pp. 189-203.

22. W.J. Kim and J.Y. Wang: Mater. Sci. Eng. A, 2007, vol. 464, pp. 23-27.

23. M. Das, G. Das, M. Ghosh, M. Wegner, V. Rajnikant, S. GhoshChowdhury, and T.K. Pal: Mater. Sci. Eng. A, 2012, vol. 558 , pp. 525-32.

24. A. Loucif, R.B. Figueiredo, T. Baudin, F. Brisset, and T.G. Langdon: Mater. Sci. Eng. A, 2010, vol. 527, pp. 4864-69.

25. S.H. Lee, Y. Saito, T. Sakai, and H. Utsunomiya: Mater. Sci. Eng. $A$, 2002, vol. 325, pp. 228-35.

26. M.R. Rezaei, M.R. Toroghinejad, and F. Ashrafizadeh: J. Mater. Process. Technol., 2011, vol. 211, pp. 1184-90.

27. M.R. Rezaei, M.R. Toroghinejad, and F. Ashrafizadeh: Mater. Sci. Eng. A, 2011, vol. 529, pp. 442-46.

28. G. Faraji, M.M. Mashhadi, and H.S. Kim: Mater. Lett., 2011, vol. 65 , pp. $3009-12$.

29. T.G. Langdon: Mater. Sci. Eng. A, 2007, vol. 462, pp. 3-11.

30. F. Salimyanfard, M. Reza Toroghinejad, F. Ashrafizadeh, and M. Jafari: Mater. Sci. Eng. A, 2011, vol. 528, pp. 5348-55.

31. C. Xu, M. Furukawa, Z. Horita, and T.G. Langdon: Acta Mater., 2003, vol. 51, pp. 6139-49.

32. Y. Tham, M. Fu, H. Hng, Q. Pei, and K. Lim: Mater. Manuf. Process., 2007, vol. 22, pp. 819-24.

33. S.H. Lee, Y. Saito, N. Tsuji, H. Utsunomiya, and T. Sakai: Scripta Mater., 2002, vol. 46, pp. 281-85.

34. R.Z. Valiev, E.V. Kozlov, Y.F. Ivanov, J. Lian, A.A. Nazarov, and B. Baudelet: Acta Metall. Mater., 1994, vol. 42, pp. 2467-75.

35. K.S. Raju, M.G. Krishna, K.A. Padmanabhan, K. Muraleedharan, N.P. Gurao, and G. Wilde: Mater. Sci. Eng. A, 2008, vol. 491, pp. 1-7.

36. Q.D. Wang, Y.J. Chen, J.B. Lin, L.J. Zhang, and C.Q. Zhai: Mater. Lett., 2007, vol. 61, pp. 4599-4602.

37. C. Chang, P. Sun, and P. Kao: Acta Mater., 2000, vol. 48, pp. $3377-85$.

38. Z. Marciniak, J.L. Duncan, and S.J. Hu: Mechanics of Sheet Metal Forming, Butterworth-Heinemann, Oxford, 2002. 